narrower question is : can we say that the imitative self-thought theory combined with the selective thinking theory is a valid account of the case of organization which we describe as social thinking ?

Dr. Bosanquet seems to admit-what I think a careful reading of his discussion will bear out-that much of his criticism of the social Imitation theory would be met in case the theory of selective thinhing were made out. I shall accordingly take up in the next issue, if possible, his objections to this latter theory.

PRINCFTON UNIVERSTY.

J. Mark Baldwin.

\title{
METHODS OF TESTING RELATIVE PITCH.
}

A comparison of the methods that have been used for testing perception of pitch is of importance, as the results that have been obtained vary considerably.

In the Tale Psychological Laboratory Studics, iS93, I., p. So, Gilbert reports experiments on the "Musical Sensitiveness of School Children.' These experiments were confined to testingr perception of pitch differences. A pipe was used by which the experimenter produced tones separated by $\frac{1}{3} \overline{2}$ of a tone, or multiples of that anount. The apparatus is described fully in his paper. The method of gradation was used. Starting from notes a considerable distance apart, the experimenter made the difference less until the subject declared that he perceived then as the same. The process was reversed and the average of the two results taken. An average of ten such experiments with each child was taken. The results indicated that children of six years could, on the average, discriminate tones $\frac{2}{2}$ of a tone apart, and that the improvement was fairly uniform to the age of 19 , at which age a difference of $\frac{3}{32}$ of a tone was, on the average, perceived.

In employing the method of gradation with a string instrument $I$ encountered the serious objection that a hypercritical attitude, either constitutional or suggested, on the part of the subject works constantly for a better, the opposite attitude for a worse record. That is, a person who fancies he notes differences where there are none perceptible by him, or confuses quality or intensity differences with pitch difference, secures a better average than one who records more accurately what his senses give him. By the method of right and wrong cases this difficulty may be avoided. Differences of quality and intensity are very likely to arise in any pipe instrument, especially when the mouth is used. Moreover, as by this method the difference in pitch con- 
tinually varies, the subject is poorly provided with a standard differ. ence with which he may compare, and from which he might distinguish qualitative differences. From Table II. it may be seen that

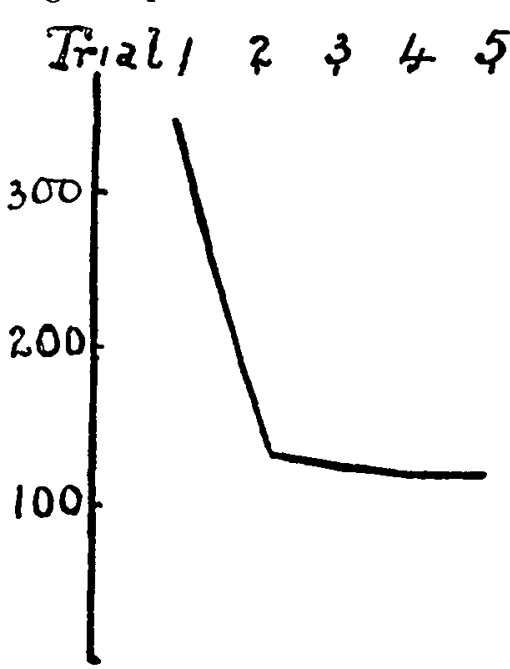

FIG I. Pcrcentage of Mean Deviation of Successive Trials. this is important. The best subjects show their superiority in perceiving notes of the same pitch as the same. The poorer subjects tend to call all notes different, confusing qualitative with pitch differences. A further objection to this method is its length.

In testing freshmen and seniors for perception of pitch, the Psychological Laboratory of $\mathrm{Co}$ lumbia University uses a wire, $\mathrm{I}$ meter long between supports, with a movabie bridge. A note is given with the bridge at $750 \mathrm{~mm}$. from one end (giving $\mathrm{F}_{1}$ ), the bridge is placed at the center, and the subject tries to reproduce the tone given. Then the original tone is again given, the bridge is placed where the subject left it, and he tries again. The average of the two results is taken. The weakness of this experiment is that the tone memory is tested as well as the tone perception; this is only partly remedied by replacing the bridge for the second trial where the subject had left it at the first trial. It is not claimed that the results are more than approximate and relative. Of those tried, Io per cent. have an error of less than .I of a tone; 53 per cent. . I to $I$ tone, and 37 per cent. more than one tone. These errors are far greater than those of school children tested by Gilbert and by me.

In examining the Columbia Laboratory method I prolonged it to ten trials, always replacing the bridge for each trial where the subject had left it at the preceding trial. I made fifteen such experiments. For each subject I computed the mean deviation, brought it to a fraction of the average error of that subject, to make it comparable with other cases, and took an average of the resulting fractions. The average deviation was 706 of the average error, which shows a large element of chance. In a similar manner I found what fraction the average deviation of the first, second, third, fourth and fifth trials were of the average deviation of the last nine trials in each experi- 
ment (see Fig. I). It is clear that the first trial is not comparable with the others. As I also found that the first trual gave an error far greater than the remaining trials, and the second trial one considerably greater, the average of these two trials indicates a perception of pitch far worse than that actually possessed. However great a number of trials is taken, this method is open to a further objection. A subject may by chance get within his power of discrimination and may remain there, for there is no apparent reason why he should move the bridge further away from the correct place (see Fig. 2). All the records on this figure were made by the same subject.

For these reasons neither Gilbert's method nor that in use at Columbia seem very satisfactory for anything like an absolute determination of pitch perception. To secure necessary thoroughness without too great expenditure of time we must look, I think, to methods suitable to use with classes. An individual test, however, is sometimes valuable to confirm the class test. The method of "right and wrong cases, in which the operator produces the tones, is too long. The subject must reproduce the tone therefore. This may be done by the voice: but in the absence of any practical phonautograph an accurate test of pitch perception cannot be obtained in this way. All wind instruments, it seems to me, interfere with the memory of sound because of the continued and varying note given during adjustment. Those that require the use of the mouth interfere with the subject's attention, and have other faults.

As an improvement on the Columbia method above described I suggest the following: Use two strings, $x$ meter long, the tension being adjusted so that the note given by one is equivalent to that given by the other when the bridge is placed, say, $750 \mathrm{~mm}$. from one end. Within an octave of middle $\mathrm{C}$, any note that can be readily checked with a tuning fork will do. The bridge should be just as high as the wire. The movable bridge should slide in a groove, and should clamp the wires with wooden surfaces pressed together by a spring. The subject should face the instrument and handle the movable bridge until he can move it without special attention to it, and until he understands what effect on pitch motion in either direction has. The purpose of using two strings and this kind of bridge is to save time, confusion and distraction of attention, all of which introduce the question of tone memory into the experiment, which is, of course, an entirely different matter from tone perception.

The bridge is put at the center of the one string and the standard note is given on the other. This the subject tries to reproduce. When he stops, the standard note is given again, and the subject tries 
again. The result of the second try is recorded for averaging. For a second experiment the standard note may be changed by placing the bridge at, say, Soo $\mathrm{mm}$. from one end of the standard string, which would be equivalent to $600 \mathrm{~mm}$. on the string which the subject uses. The error at the second attempt is noted, corrected by being multiplied by $\frac{5}{4}$, and averaged with the first record. The average can

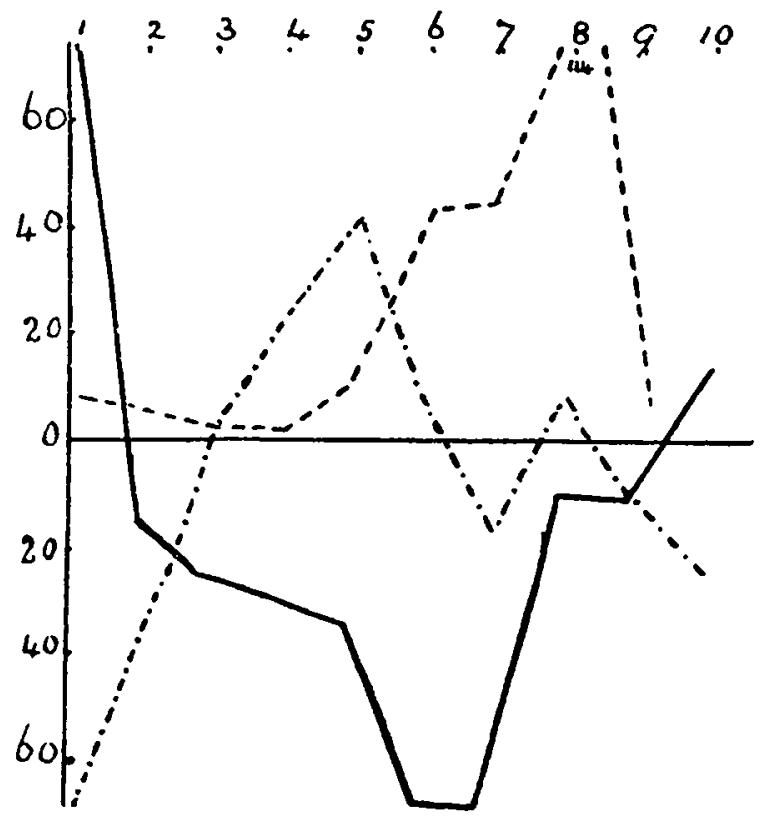

FIG. 2. Three records made by a graduate student according to Columbia method. The ordinates show the errors in num.

easily be reduced to fractions of a tone. These two tests can readily be carried out in five minutes with the average scholar.

Working with a rather poor instrument $I$ found that, in 72 trials, the mean deviation was thus reduced to .48 of the average error, as contrasted with . 706 by the present Columbia method.

I think that methods suited for use with a class are better. I first used tuning forks that gave respectively $5^{1} 2$ and $5^{1} 6$ double vibrations per second. By adding wax I could get intervals of $\frac{1}{6}$, $\frac{1}{14}$ and $\frac{1}{26}$ of a tone, without causing thereby any marked differences in quality between the forks owing to the mass of wax on either of them. To find what interval people capable of musical training possess, I secured the cooperation of a 'mixed' church choir, and of the ladies of two of Professor Farnsworth's classes at Teachers College. Pro- 
fessor Farnsworth and the choirmaster kindly' graded the subjects into classes ' $a$,' ' $b$,' and ' c,' according to musical ability.

I first required the subjects to say which of two notes given was higher. The results are given in Table $\mathrm{I}$. They show that musical

TABLE I.

\begin{tabular}{|c|c|c|c|c|c|c|c|}
\hline Interval & $\frac{1}{8}$ & $I^{2}$ & \multicolumn{5}{|c|}{$2_{2}^{2}$ tone. } \\
\hline No. of trials & 10 & 20 & 10 & & & & \\
\hline Class $a$ & 95.7 & 635 & \multicolumn{3}{|c|}{$5^{\delta}$ per cent. right. } & 14 & bjects. \\
\hline “ $b$ & 69 & 48 & 37 & $"$ & “ & 9 & \\
\hline$" c$ & 50 & 65 & 54 & " & "“ & 8 & “" \\
\hline Unclassified & 70 & 55 & 49 & “ & $"$ & 8 & “ \\
\hline
\end{tabular}

ability corresponds rather closely to capacity to perceive pitch differences. Further, that by this method an interval of $\frac{1}{6}$ tone is probably a little too small for eliminating those that are incapable of musical training. Some of the better musicians showed a tendency to call the lower notes the higher, and conversely, at every trial, a fact that obviously discredits this method.

I then required the same classes to tell whether the tones given on the forks were the same or different. Table II. shows the results.

TABLE II.

\begin{tabular}{|c|c|c|c|c|c|c|c|c|c|}
\hline \multirow{2}{*}{$\begin{array}{l}\text { Interval } \\
\text { No. of trials }\end{array}$} & & $\begin{array}{r}\frac{1}{6} \\
20\end{array}$ & & & $\begin{array}{l}1^{2} 5 \\
30\end{array}$ & & \multicolumn{3}{|c|}{$\begin{array}{l}\frac{1}{28} \text { tone. } \\
20\end{array}$} \\
\hline & 'Same.' & $\begin{array}{c}\text { 'Differ- } \\
\text { ent ' }\end{array}$ & Total & 'Same.' & $\begin{array}{l}\text { Differ- } \\
\text { ent }\end{array}$ & Total & 'Same' & $\begin{array}{c}\text { 'Differ- } \\
\text { ent ' }\end{array}$ & Total. \\
\hline Class $a$ & 80 & 85 & 833 & 677 & 61.7 & 647 & 75 & 61.7 & 70.7 \\
\hline & 71.4 & 90 & 83 & 61 & 72.4 & 68 & 61.6 & 70 & 66 \\
\hline " $c$ & 66 & 96 & 81.5 & 68 & 81.3 & 74.7 & $5^{6}$ & 56 & 56 \\
\hline Unclassified & $33 \cdot 3$ & 100 & 66.6 & 50 & 63.3 & 567 & $\mathrm{~J} 3 \cdot 3$ & 66.3 & 40 \\
\hline
\end{tabular}

The numbers indicate the per cent. of answers right.

The words 'same,' ' different,' there indicate that the per cent. given below is the number of right answers given when the tones struck were the same or different. An equal number of each was given in the experiments. It is clear from these figures that when the subject begins to get uncertain, his difficulty is usually not so much in perceiving that the tones are different when they are different, as in telling that the same notes have been struck, $i . e$. , in distinguishing qualitative from pitch differences, or, perhaps, in checking his imagination.

In the use of the last method I judged that $\frac{1}{6}$ tone is too small a difference to select the best ears, too large to indicate the really deficient ones. I therefore selected $\frac{1}{3}$ tone and $\frac{1}{5}$ tone as the intervals for 
a scries of tests with school children. As I could not get suitable tuning forks I strung two wires so as to give the same note for their full length, namely middle $C$, and, by means of a bridge, secured the above intervals. I gave twenty trials at each interval, in alternate series of ten each, making the number of 'sames' and 'differents' equal. Tables III. and IV. and Fig. 3 show the results. I cannot

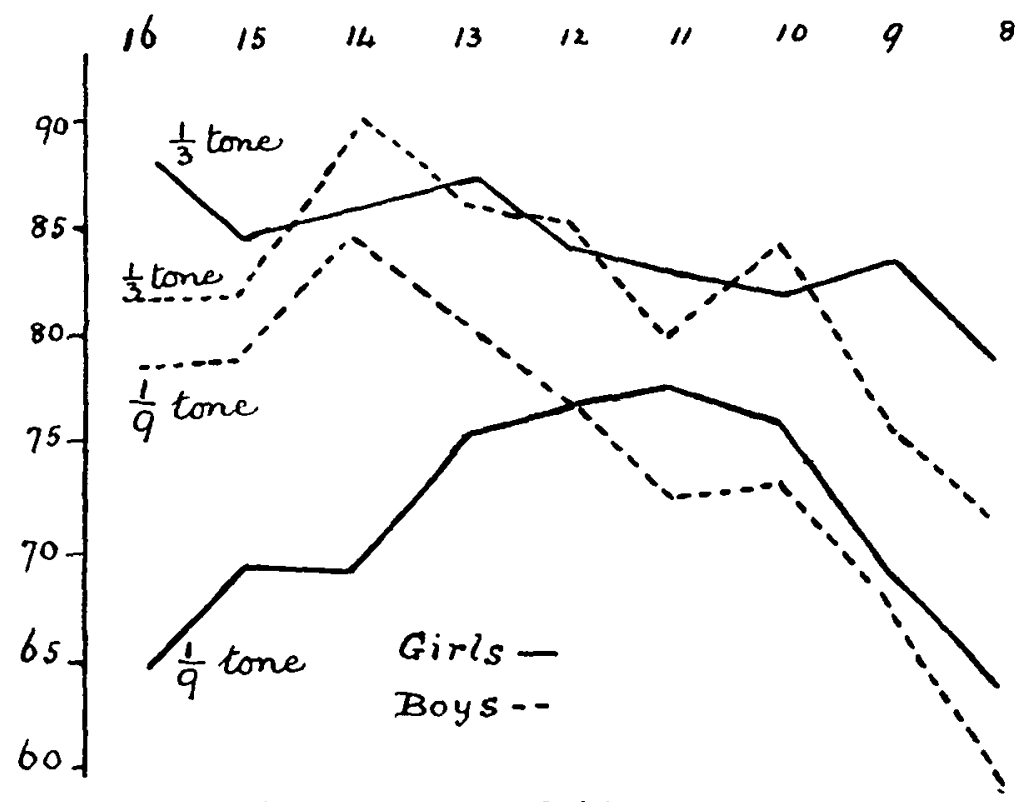

FIG. 3. Percentage of Right Answers.

TABI.E III.

Percentage of Subjects Faifing to get more than 75 Per Cent. Right.

Age in years

Number of subjects

Girls, $\frac{1}{3}$ tone

Girls, $\frac{1}{9}$ tone

Age in years

Number of subjects

Boys, $\frac{1}{3}$ tone

Boys, of tone

$\begin{array}{rrrrrrrrr}16 & 15 & 14 & \text { I3 } & \text { I2 } & \text { II } & \text { IO } & 9 & 8 \\ 5 & 17 & 28 & 41 & 27 & 30 & 29 & 33 & 17 \\ 0 & 23 & 18 & 15 & 19 & 33 & 34 & 34 & 35 \\ 100 & 76 & 68 & 66 & 52 & 50 & 58 & 90 & 95 \\ 16 & 15 & 14 & 13 & 12 & 11 & 10 & 9 & 8 \\ 5 & 10 & 28 & 41 & 27 & 30 & 29 & 33 & 17 \\ 40 & 30 & 7 & 20 & 23 & 35 & 29 & 50 & 60 \\ 20 & 50 & 25 & 35 & 48 & 58 & 50 & 80 & 80\end{array}$

TABLE IV.

Percentage of Correct Answers.

$\begin{array}{lllllllllr}\text { Age } & 16 & 15 & 14 & 13 & 12 & 11 & 10 & 9 & 8 \\ \text { t tone } & 86 & 84 & 88 & 88 & 85 & 82 & 84 & 78 & 75 \\ \text { t tone } & 72 & 73.5 & 77.5 & 78.7 & 77 & 75 & 75 & 68 & 59\end{array}$


explain the poorer showing of the older girls with the small interval as shown by the curve. Younger girls did better at the same time under the same circumstances.

I examined the papers, taken at random, of thirty-five boys and girls, and found the same tendency as in the former experiment to err chiefly in telling which notes were the same. Out of 308 errors in I,400 answers : 178 , or $57.8 \%$, were 'same' called different; I 30 , or $42.2 \%$, were 'different' called same; in conducting the experiment the instrument was kept from view, one or more teachers watched with me for any signs of copying or prompting, and, especially, I was careful to get the interest of the children in securing correct results. The first note must be dampened before the second is sounded, so as to prevent beats. Great care must be used to strike the string at the same distance from the ends and in just the same way.

The fact that the subjects discriminated an interval of one third tone not much better than one of one ninth tone may. perhaps, be taken to indicate that the growth in accuracy is a matter of cerebral more than of aural development. Another indication in this direction is that the older children in a class, who are more likely to be 'left backs' did rather worse than the rest of the class, as a rule.

Two or three of the teachers remarked on the apparent connection between general intellectual inferiority and inferiority according to these tests.

PERCY Hughes.

Columbia University. 